\author{
Michał RAJZER ${ }^{1}$ \\ Opiekun naukowy: Natalia OSIŃSKA ${ }^{2}$ \\ DOI: https://doi.org/10.53052/9788366249837.36
}

\title{
NISKOBUDŻETOWY PROTOTYP SPEKTROFOTOMETRU OPEN SOURCE
}

\begin{abstract}
Streszczenie: Artykuł dotyczy konstrukcji niskobudżetowego spektrofotometru o możliwości badania próbek o bardzo niskich objętościach. Celem artykułu jest przedstawienie kompletnego projektu spektrofotometru.
\end{abstract}

Słowa kluczowe: Spektrofotometria, Open Source Hardware, IoT

\section{OPEN SOURCE LOW COST SPECTROPHOTOMETER PROTOTYPE}

\begin{abstract}
Summary: The article focuses on the construction of a low cost spectrophotometer that is capable of analysing extremely small volumes. The goal of the article is to show the complete project of the spectrophotometer.
\end{abstract}

Keywords: Spectrophotometry, Open Source Hardware, IoT

\section{Introduction}

Nowadays the need to analyse small quantities of liquids in biological and chemical laboratories is growing at an incredible pace. This has led to the creation of many creative solutions. One of these is the use of spectrophotometry. Many devices using this technique have been created but none have yet been both open source, affordable and functional. This article aims to create one that fulfils all of these criteria while allowing the end user for further customization to best suit their use case. Due to said circumstances, the project as a whole was inspired by a video created by The Thought Emporium on YouTube.

\footnotetext{
${ }^{1}$ Uczeń, Akademickie Dwujęzyczne Liceum Ogólnokształcące Oxford Secondary School, e-mail: michal.rajzer03 gmail.com

${ }^{2}$ Inż. Inżynierii Biomedycznej, Akademickie Dwujęzyczne Liceum Ogólnokształcące Oxford Secondary School, natalia.osinska@oxford-centre.network
} 


\section{Principle of operation}

A simplified version of a spectrophotometer is presented below (fig. 1). The light emitted from the light source travels through the sample. It is them collimated through a small hole below the sample holder. Then the beam reflects off a mirror and gets diffracted by a diffraction grating. This creates a separation of the wavelengths that are left in the spectrum after passing through the sample. This split beam is then recorded by a digital camera. The image from the camera is then transmitted to a computer for processing.

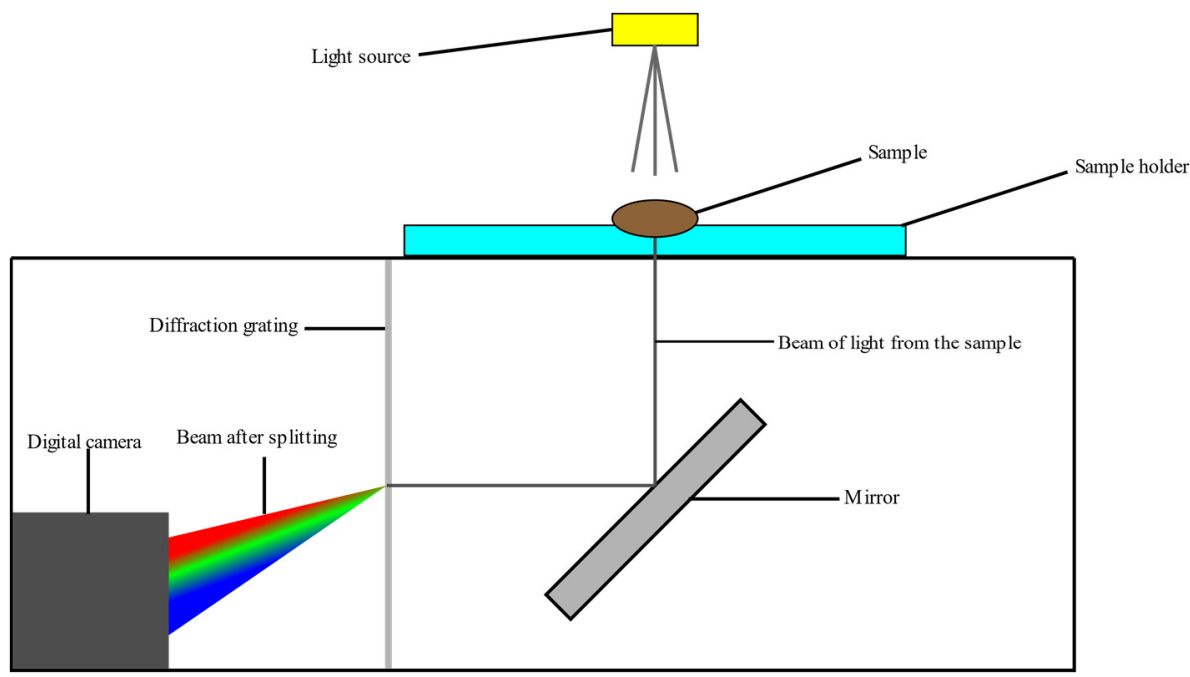

Figure 1. Spectrophotometer

An example view from the camera is presented below (fig. 2). The darker parts of the spectrum are the wavelengths that the sample absorbed. This darkening is useful as the ratio of the amount of light blocked to the amount of light transmitted is often linearly correlated with the amount of substance dissolved in the sample.

Figure 2. Example view from the camera

In order to ensure ease of use for the end user a python script is provided that displays the current view of the spectrum visible by the camera in a browser window which as well provides manual controls and detailed analysis of the spectrum.

\section{Physical construction}

\subsection{List of components}

The device itself consists of $43 \mathrm{~d}$ printed parts: the sample holder, the shade box, the electronics enclosure, and the optical enclosure. Besides the $3 \mathrm{~d}$ printed parts, a couple 
off the shelves components are needed such as: Raspberry Pi Zero W, 5V USB power supply, 32GB SD card Raspberry Pi Zero Camera (OV5647), diffraction grating (1000 lines/mm, $30 \mathrm{~mm}$ by $80 \mathrm{~mm})$, first surface mirror $(30 \mathrm{~mm}$ by $70 \mathrm{~mm})$, microscope slide $(76.2 \mathrm{~mm}$ by $25 \mathrm{~mm}$ ), 5mm white LED, MosFET (STP65NF06), $330 \mathrm{ohm}$ resistor, perforated copper dot board, miscellaneous wires, gauge 3 acupuncture needle, super glue, soldering iron. Optional: matte black paint (Black 3.0).

\subsection{Assembly}

In order to assemble the device first $3 \mathrm{~d}$ print the required parts included on GitHub, then you should solder the electronics components accord to the schematic below (fig. 3). Optionally, before assembly, the insides of the optical enclosure, sample holder, and the shade box can be painted with matte black paint in order to minimize the amount of stray light interfering with the equipment. Install the mirror in the mirror holder using a drop of super glue to secure it in place. Next install the mirror holder into the optical enclosure using a piece of $1.75 \mathrm{~mm} 3 \mathrm{~d}$ printing filament as the hinge pin. Secure it by using a soldering iron set to 220 degrees Celsius to weld the pin to the mirror holder (fig. 4). Next set the soldering iron to around 300 degrees and use it to heat up the needle, and then use it to create a hole, aligned with the sample holder, in the top part of the optical cover. Next screw in the m3 screw into the screw hole, using nuts on both sides. Then insert the diffraction grating into the designated slot (fig. 4) and place the camera and route the ribbon connector through the designated hole (fig. 4). Next align the sample holder and the shade box. For the first test connect the electronics and connect the Raspberry Pi to a display. Next using the command "raspistill -k" you can preview the view of the camera, and shine the light through the setup to align the camera so that the spectrum of light is in view and preferably in the centre of the viewport. use the adhesive at the back of the camera module to fix it in place. You can close the window by typing ' $x$ ' first and then pressing 'enter'. Next shutdown all the electronics and disconnect them. Afterwards assemble the side cover, and the sample holder. Insert the microscope slide into the slot in the sample holder. Finally glue in the LED into the holder in the shade box.

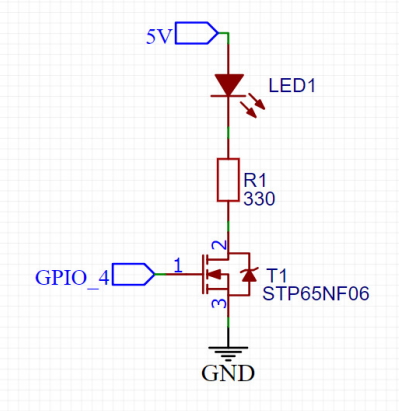

Figure 3. Electric schematic 


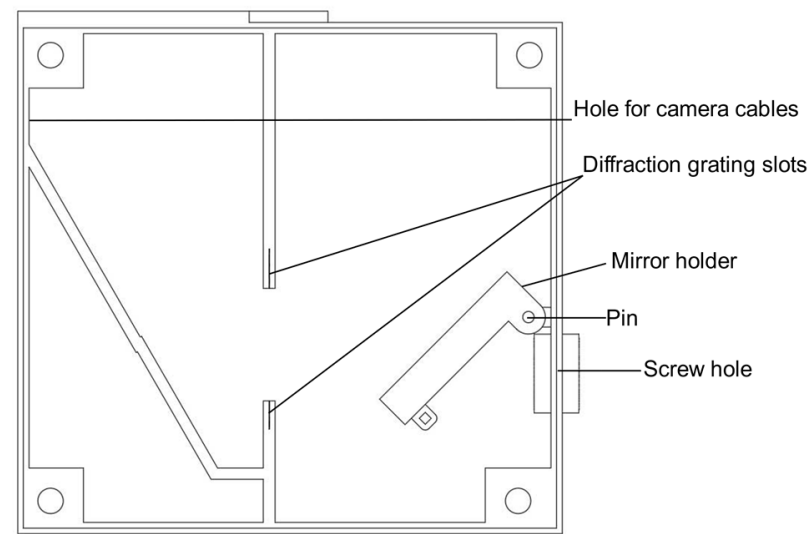

Figure 4 (right) Mechanical diagram

\subsection{Software setup}

The software was developed using python which is an interpreted language and so can be used on many different platforms. The suggested setup is to download the Raspbian operating system, boot the Pi and configure Wi-Fi settings as well as enable the Camera in Preferences. Next download the software files from GitHub and unpack the .zip file and add then modify the rc.local file using the command "sudo nano /etc/rc.local" and add the line "python3 \{your path\}/main.py". Lastly turn off the Pi and connect all of the electronics and then boot up the Pi. Now the webserver should be running and the Pi should display the view of the camera from on the website situated its IP address.

\subsection{Online documentation}

The online documentation, and all downloads of the device are freely available at https://github.com/MichalRajzer/OpenSourceSpec In order to ensure the practicality of the device, additional features stemming from pull requests might be added to the repository in the future. The project as a whole is shared under the MIT License.

\section{Conclusion}

In conclusion the paper's main objective was fulfilled as the described device costs below $\$ 100$ and is able to offer the required measurements to be functional. Furthermore it can be improved by the end used due to being constructed from mostly $3 \mathrm{~d}$ printed parts, which due to the open source nature of the project can be easily modified to suit the specific needs of the end user.

\section{REFENCES}

1. Building a Nanodrop Style UV/Vis Spectrometer, The Thought Emporium, https://youtu.be/pIk8I10ZmYY $19^{\text {th }}$ January 2019, date accessed, $31^{\text {st }}$ October 2021 